\title{
MICRO-MATERIAL HANDLING EMPLOYING E-BEAM GENERATED TOPOGRAPHIES OF COPPER AND ALUMINIUM
}

\author{
S. Matope ${ }^{1 *}$, A.F. van der Merwe ${ }^{2}$, R. Nemutudi ${ }^{3}$, M. Nkosi $^{4} \&$ M. Maaza \\ 1,2 Department of Industrial Engineering \\ University of Stellenbosch, South Africa \\ ${ }^{1}$ smatope@sun.ac.za, 2avdm@sun.ac.za \\ 3,4,5 Department of Material Science \\ iThemba Labs, South Africa \\ ${ }^{3}$ rudzi@tlabs.ac.za, ${ }^{4}$ mlungisin@tlabs.ac.za, ${ }^{5}$ maaza@tlabs.ac.za
}

\begin{abstract}
This paper focuses on the employment of copper and aluminium in a micro-material handling system actuated by Van der Waals forces. Electron beam (e-beam) evaporator deposited both materials on a silicon substrate at a rate of 0.6-1.2 Angstroms/ second, vacuum pressure between $2 \times 10^{-6}$ and $3 \times 10^{-6} \mathrm{mbar}$, and at a current less than $10 \mathrm{~mA}$. A Veeco NanoMan V Atomic Force Microscope with Nanoscope version 7.3 software was used to analyse the root mean square (rms) surface roughnesses of the generated topographies. Rumpf-Rabinovich's rms formula was used to determine the Van der Waals forces exerted by the surfaces. It was synthesised that an e-beam deposition of 7 minutes' duration on both materials produced an optimum micro-material handling solution, with copper suitable for the pick-up position and aluminium for the placement position.
\end{abstract}

\section{OPSOMMING}

Die fokus van die artikel is op die gebruik van koper en aluminium in ' $n$ mikromateriaalhanteringstelsel, aangedryf deur Van der Waalskragte. 'n Elektronstraalverdamper plaas albei materiale op ' $n$ silikonbasis teen ' $n$ tempo van 0.6-1.2 Angstrom/ sekonde, vakuumdruk tussen $2 \times 10^{-6}$ en $3 \times 10^{-6} \mathrm{mbar}$, en teen ' $\mathrm{n}$ stroom van minder as $10 \mathrm{~mA}$. ' $\mathrm{n}$ Veeco NanoMan $\mathrm{V}$ Atomic Force mikroskoop, met Nanoscope 7.3 programmatuur is gebruik om die wortel-gemiddelde-kwadraat (wgk) oppervlak ruheid van die gegenereerde topografieë te analiseer. Rumpf-Rabinovich se wgk-formule is gebruik om die Van der Waalskrage wat deur die oppervlaktes uitgeoefen word te bepaal. Dit is vasgestel dat ' $n$ elektronstraalafsetting van 7 minute op albei materiale die optimale materiaalhanteringoplossing bied, met koper geskik vir die optelposisie en aluminium vir die plasingsposisie.

\footnotetext{
${ }^{\overline{1}}$ The author was enrolled for a PhD (Manufacturing Engineering) degree in the Department of Industrial Engineering, University of Stellenbosch.

* Corresponding author.
} 


\section{INTRODUCTION}

In a micro-manufacturing environment, challenges arise when moving minute work parts from one place to another because of prevalent micro-forces. Among other forces, Van der Waals forces are predominant during micro-material handling, and they make it very difficult to release a micro-work part once picked. In this paper, e-beam evaporation is used to generate surface topographies of copper and aluminium for micro-material handling purposes. The generated surface roughnesses have characteristic root mean square (rms) values, which are used to optimise the efficacy of a micro-material handling system.

\subsection{Background}

The worldwide demand for miniature products has increased (Raatz \& Hesselbasch [11]). The conventional macro-machines used in macro-material handling have proved to be very inefficient when applied to micro-manufacturing. This has led to the advent of microfactories which use miniature machines to assemble minute products (Okazaki et al. [8]). Gravity has proved to be effective in releasing conventional macro-products, but ineffective when releasing micro-materials (Fukuda \& Arai [5]). So methods other than gravity have to be devised to release a micro-work part effectively. In this case e-beam evaporation is used to generate surface roughnesses of varying rms values, to improve the efficacy of a micro-material handling system.

\subsection{Forces acting during micro-material handling}

The forces that affect most materials during micro-material handling include electrostatic, surface tension, and Van der Waals forces. The first two are relatively easy to eliminate. The anti-static mat can be used to remove the effect of electrostatic force (Van der Merwe \& Matope [15], Matope \& Van der Merwe [8]), and a micro-electric heater can be used to eliminate the surface tension force, which depends on high levels of humidity (Fukuda $\&$ Arai [5]). So this paper investigates another technique: the e-beam generated rms surface roughnesses, which are aimed at manipulating the Van der Waals forces exerted between interacting surfaces during micro-material handling.

\subsection{Van der Waals forces and concepts}

Van der Waals forces may be simply defined as natural attractive forces between two particles or surfaces in close proximity (Fukuda \& Arai [5], Parsegian [10]). An advanced definition would be that Van der Waals are short-range forces that act when surfaces are sufficiently close together, and are due to spontaneous electrical and magnetic polarisations that cause a fluctuating electromagnetic field within the medium and in the gap between the surfaces involved (Debrincat et al. [2], Zhang et al. [16]).

The root mean square (rms) value is a measure of the roughness of a given surface topography. The intensity of Van der Waals forces is inversely proportional to the rms values of the interacting materials, while they are directly proportional to the Hamaker coefficients of the given materials. A Hamaker coefficient is a material property of matter that reflects the intensity of the Van der Waals forces exerted by a given substance (Parsegian [9]).

The Rumpf-Rabinovich equation (1) gives the scientific relationship of the Van der Waals forces to the two above-mentioned parameters (Rabinovich et al. [12]). In this paper it is used to determine the overall intensity of Van der Waals forces experienced between interacting surfaces.

\subsection{Micro-material handling}

Micro-material handling refers to picking and placing micro-materials in a manufacturing environment (Fukuda \& Arai [5], Matope \& Van der Merwe [8]). Micro-materials range in size from 1 micron to 1 millimetre. Figure 1 shows a micro-material handling system in 
which a micro-gripper $(C)$ picks a micro-work part (B) from the pick-up position (A), and transfers it and releases it at placement position (D).

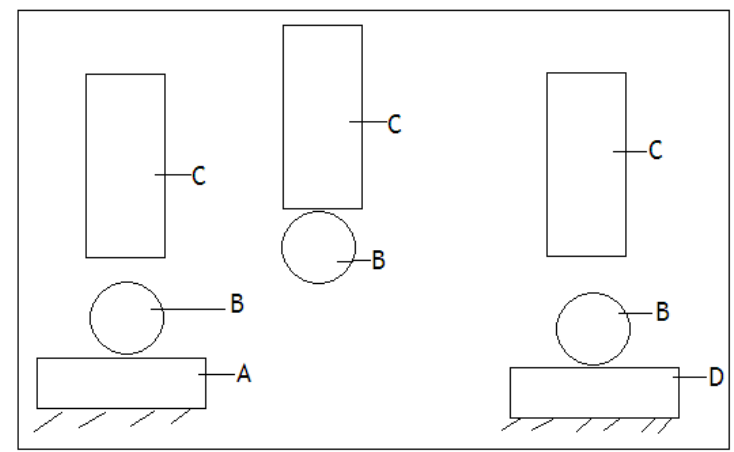

Figure 1: Micro-material handling system

\section{ELECTRON BEAM EVAPORATION PROCESS DESCRIPTION}

\subsection{Main parts of the e-beam evaporator}

It is necessary to describe briefly the e-beam evaporator. The evaporator consists of a top area in which a quartz crystal monitor, an electron gun with three hearths (crucibles), and a sample changer are located. The bottom part consists of the ion pumps, sublimation pumps, and a cryopanel. The top area can be shielded from the bottom chamber by means of a baffle valve on to which an 0-ring is fitted. This valve is usually closed, maintaining a pressure lower than $1 \times 10^{-7} \mathrm{mbar}$ in the bottom area, while the necessary cleaning of the crucibles and loading of samples is performed. The pressure at the bottom is maintained by keeping the ion pumps on. The ion pump consists of an enclosure containing one or more pumping elements, surrounded by a strong magnetic field. The pumping element consists of a multi-cell anode structure between two titanium cathode plates.

\subsection{Creation of vacuum pressure in an e-beam evaporator}

A voltage of about $6000 \mathrm{~V}$ is maintained between the anode and cathode. Electrons, attracted towards the anode, are forced into a spiral path by the presence of the magnetic field. This results in a high probability of collision between electrons and gas molecules. The collisions produce gas ions and more electrons. Positively-charged gas ions are then accelerated towards the titanium cathode plates, titanium atoms being sputtered off during the process. The titanium atoms form stable compounds with atoms such as oxygen and nitrogen, causing a gettering action. The gettering action of the ion pumps can be increased by sublimation and cryo-pumping. The latter two pumping actions are only employed on the day on which the actual evaporations are done.

Up to three different elements can be evaporated sequentially during each e-beam operation. The crucibles are cleaned before each evaporation to avoid possible contamination by previously-evaporated materials. The samples, mounted on circular aluminum holders, are then put on to the sample changer, which can accommodate up to six holders. After the necessary cleaning operations have been performed, the top section of the evaporator can be pumped down. The initial pumping is done with a roughing pump to a pressure below $1 \times 10^{-1}$ mbar, after which a turbo pump is used to increase the vacuum. The action of the turbo pump is sufficient to pump the top part to pressures below $1 \times 10^{-5}$ mbar overnight.

On the day of the evaporation, the baffle valve is opened and liquid nitrogen cryo-trapping starts to improve the vacuum further. Condensation vapours such as $\mathrm{H}_{2} \mathrm{O}$ and $\mathrm{CO}_{2}$ are trapped on the cooled surface of the cryopanel. At the same time, non-condensable gases are carried down by the condensable vapour and trapped within the pore structure of the 
condensate, thereby further lowering the pressure. When the liquid-nitrogen cooled cryopanel is sufficiently cold, the sublimation pump is started - a titanium wire from which titanium is sublimated on to the cryopanel. This sorption area of titanium further reduces the vacuum to the $10^{-7} \mathrm{mbar}$ range, since the gettering action is increased.

\subsection{E-beam evaporation and deposition on samples}

After the material to be evaporated has been preheated to reduce spattering and gaseous outbursts, the actual evaporation can be carried out. The system is fitted with a shutter that can be opened or closed by means of magnets. The pressure during deposition is within the range of $1 \times 10^{-7}$ and $3 \times 10^{-6} \mathrm{mbar}$. Multilayers can be deposited sequentially without breaking the vacuum, using an electron gun. This consists of a tungsten filament that produces electrons that are focused on the crucible by a magnetic field, as in Figure 2. By increasing the electron-beam current from 0 to $750 \mathrm{~mA}$, the output power of the electron gun can be changed while maintaining the output voltage at $4 \mathrm{kV}$. Depositions are contamination-free, and no impurities in the deposited layers can be observed within the detection limits of Rutherford Back Scattering (RBS) analysis. Film thickness is measured with a quartz monitor during evaporation. The accumulation of material on the vibrating quartz crystal causes a frequency change in the crystal. This information is then fed into a microprocessor that calculates the rate of evaporation as well as the deposited film thickness.

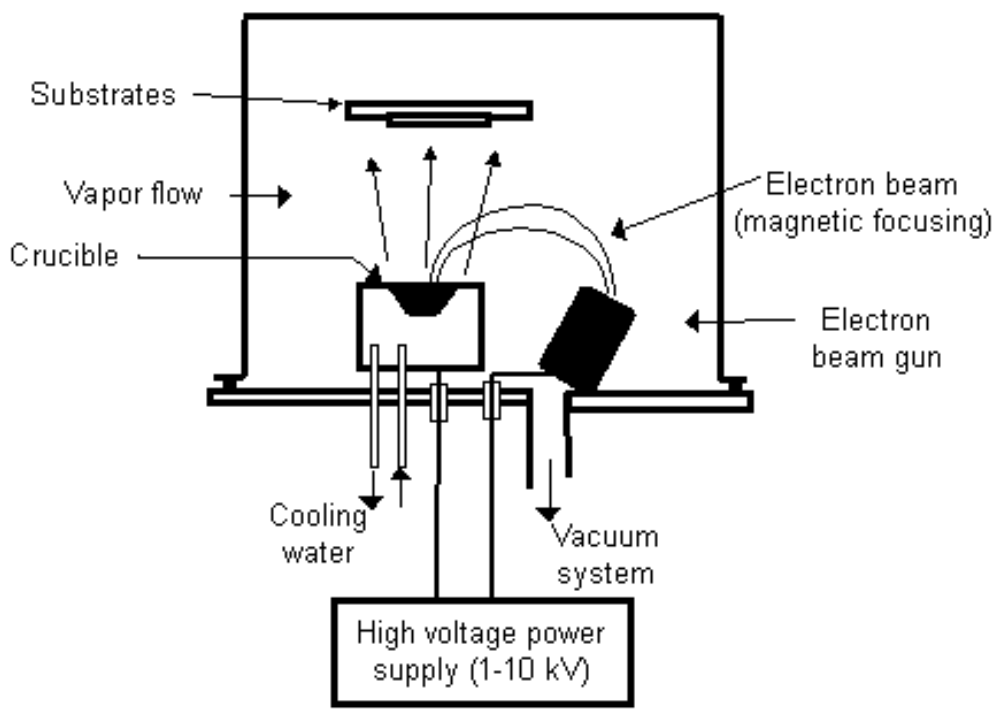

Figure 2: E-beam experimental setup

\section{EXPERIMENTAL DETAILS}

The main apparatus used were the e-beam evaporator, the Veeco NanoMan V Atomic Force microscope with Nanoscope version 7.3 software, and the ultrasonic cleaning machine. The materials used in the preparation of samples were silicon substrates, copper, and aluminium. The latter two are also referred to as the target materials. The cleaning agents were methanol, acetone, trichlorethyhlene, de-ionised water, and $20 \%$ hydrofluoric acid solution.

The silicon substrates were washed in an ultrasonic bath of methanol, acetone, and trichloroethylene respectively. They were subsequently washed in acetone, methanol, and de-ionised water, and then in $20 \%$ hydrofluoric acid solution using the ultrasonic machine. Later they were rinsed in de-ionised water. The cleaning process was intended to remove 
the oxide layers and other impurities that could hinder an effective e-beam deposition of the target material.

Copper and aluminium were then put into the crucibles and the silicon substrates were mounted in the e-beam evaporator. The machine was closed and evacuated for 24 hours to a vacuum pressure of approximately $2 \times 10^{-6} \mathrm{mbar}$. Then six e-beam depositions of each target material on the silicon substrate were done. Different deposition times were done, and Nanoscope Version 7.3 was used to analyse the generated surfaces. The experimental results are shown in Table 1 and in Figures 3 to 15. The e-beam deposition rates were within the range of 0.6-1.2 Angstroms/ second, at vacuum pressures ranging between $2 \times 10^{-6}$ and $3 \times 10^{-6} \mathrm{mbar}$, and at a current less than $10 \mathrm{~mA}$. The next section details the experimental results.

\section{EXPERIMENTAL RESULTS}

Table 1 shows the durations of e-beam depositions and the resulting copper and aluminium film thickness on silicon substrates. The results were then plotted in Figures 3, 16, and 17. Figures 4 to 15 show the surface topographies as analysed by Nanoscope Version 7.3 software.

\begin{tabular}{|c|c|c|c|c|}
\hline \multirow{2}{*}{$\begin{array}{c}\text { Duration of } \\
\text { deposition, minutes }\end{array}$} & \multicolumn{2}{|c|}{$\begin{array}{c}\text { Thickness of deposition, } \\
\text { Angstroms }\end{array}$} & \multicolumn{2}{c|}{ Surface roughness, rms } \\
\cline { 2 - 5 } & Copper & Aluminium & Copper & Aluminium \\
\hline 2 & 132 & 60 & 2.4 & 3.31 \\
\hline 5 & 378 & 66 & 2.72 & 1.71 \\
\hline 7 & 510 & 150 & 38.3 & 0.591 \\
\hline 10 & 654 & 600 & 51.8 & 17.5 \\
\hline 15 & 840 & 624 & 75.8 & 28.9 \\
\hline 20 & 984 & 654 & 217 & 8.59 \\
\hline
\end{tabular}

Table 1: The deposition of copper and aluminium on silicon substrate

Layer thickness against time

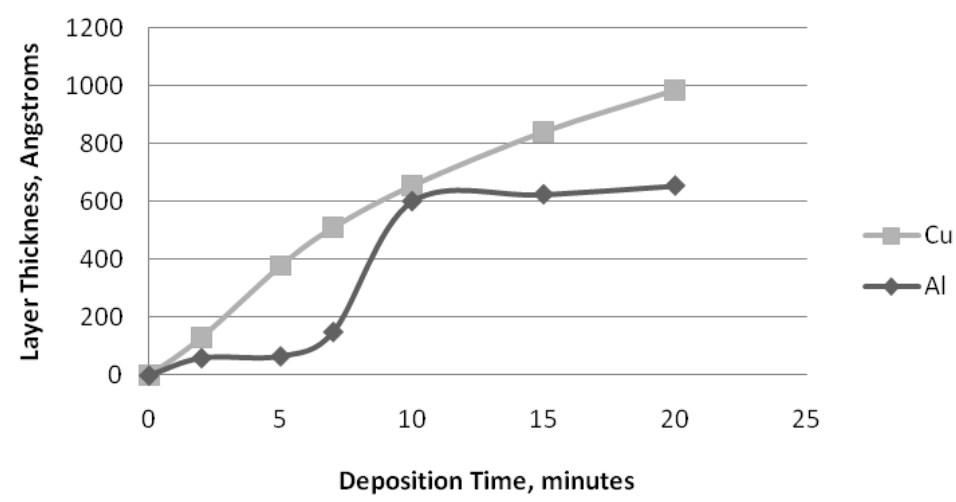

Figure 3: E-beam deposition's layer against time for copper ( $\mathrm{Cu}$ ) and aluminium (Al) 


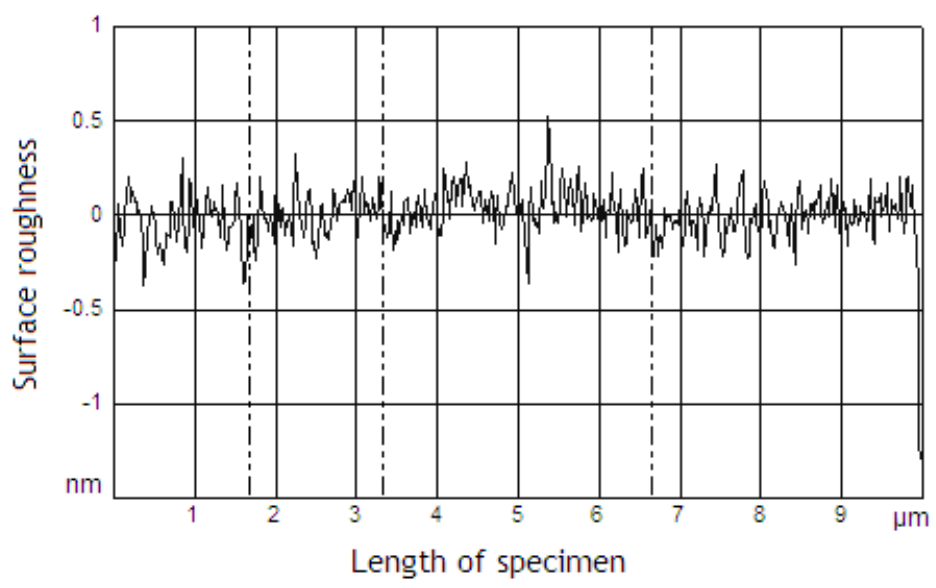

Figure 4: Atomic Force micrograph of copper deposited for 2 minutes

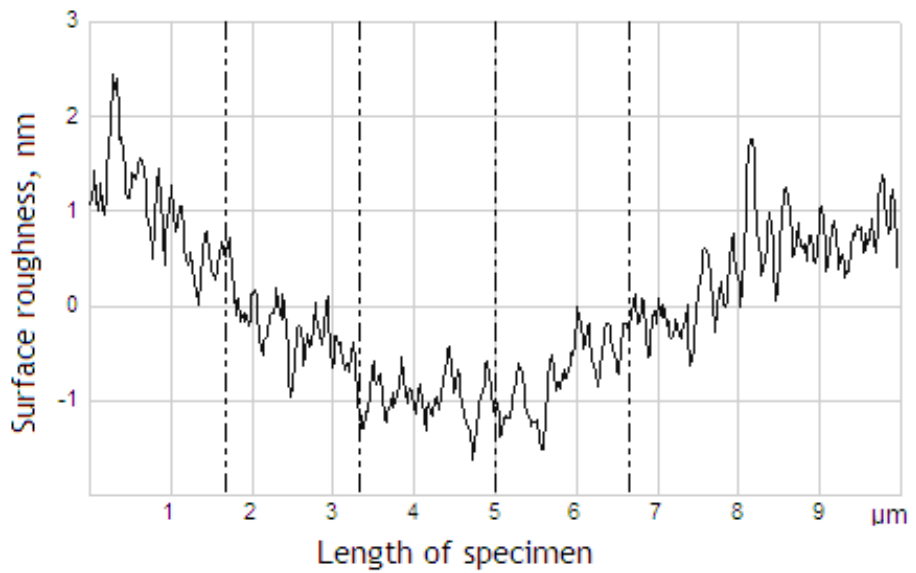

Figure 5: Atomic Force micrograph of aluminium deposited for $\mathbf{2}$ minutes

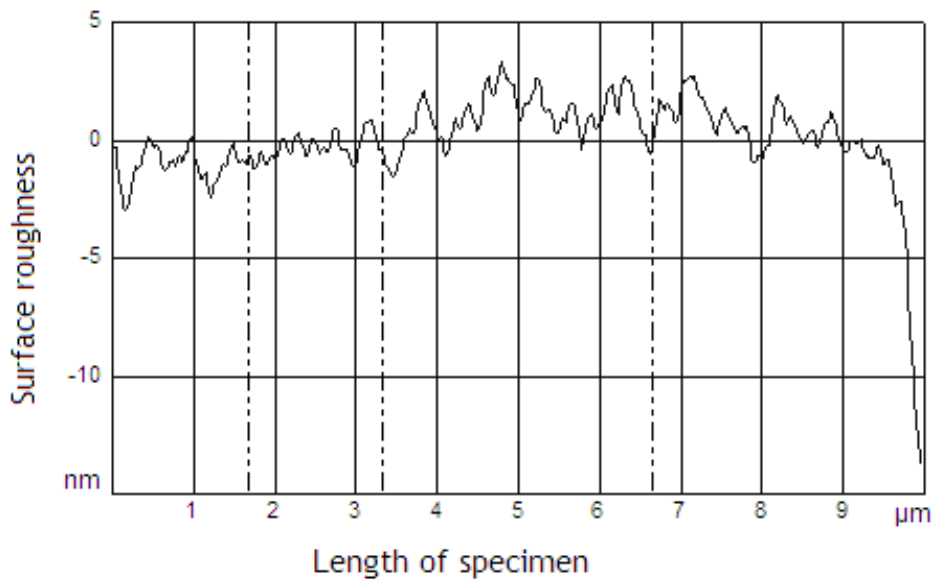

Figure 6: Atomic Force micrograph of copper deposited for 5 minutes 


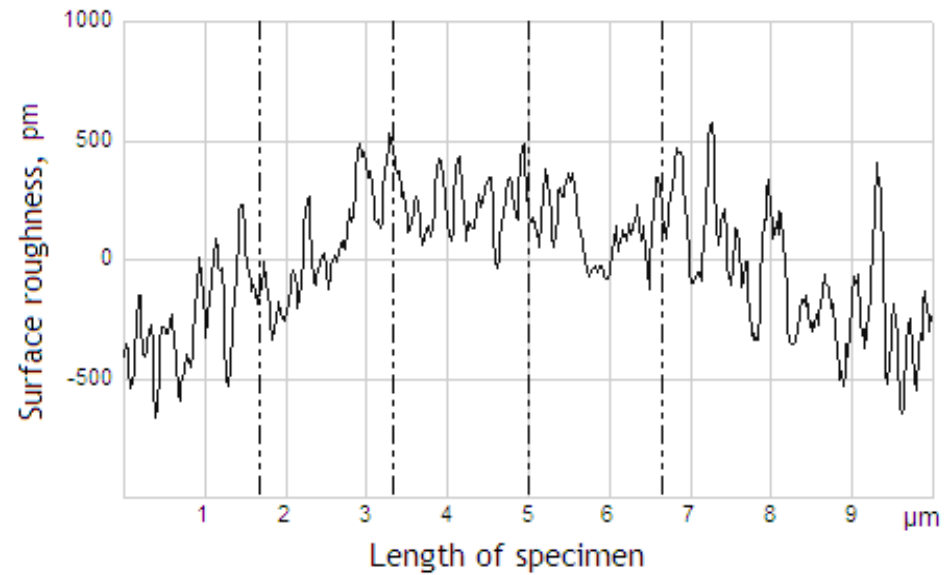

Figure 7: Atomic Force micrograph of aluminium deposited for 5 minutes

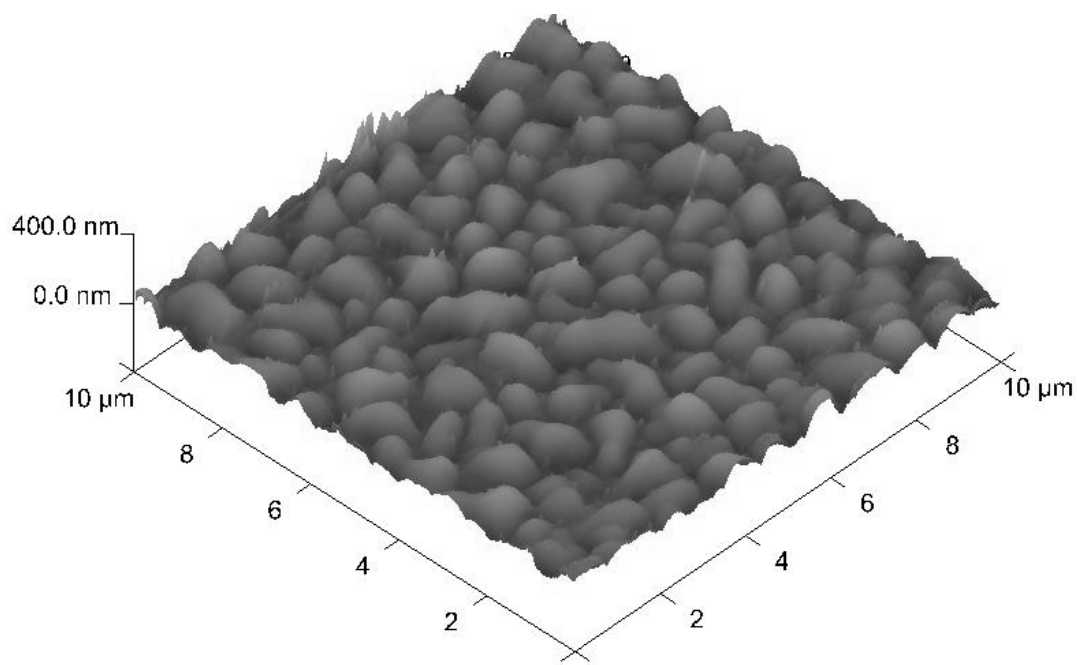

Figure 8: Atomic Force micrograph of copper deposited for 7 minutes

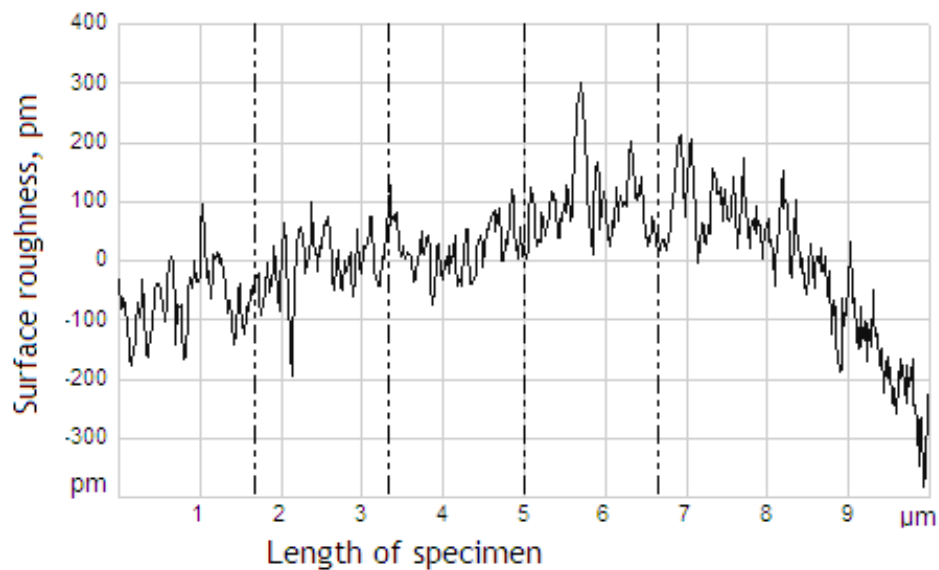

Figure 9: Atomic Force micrograph of aluminium deposited for 7 minutes 


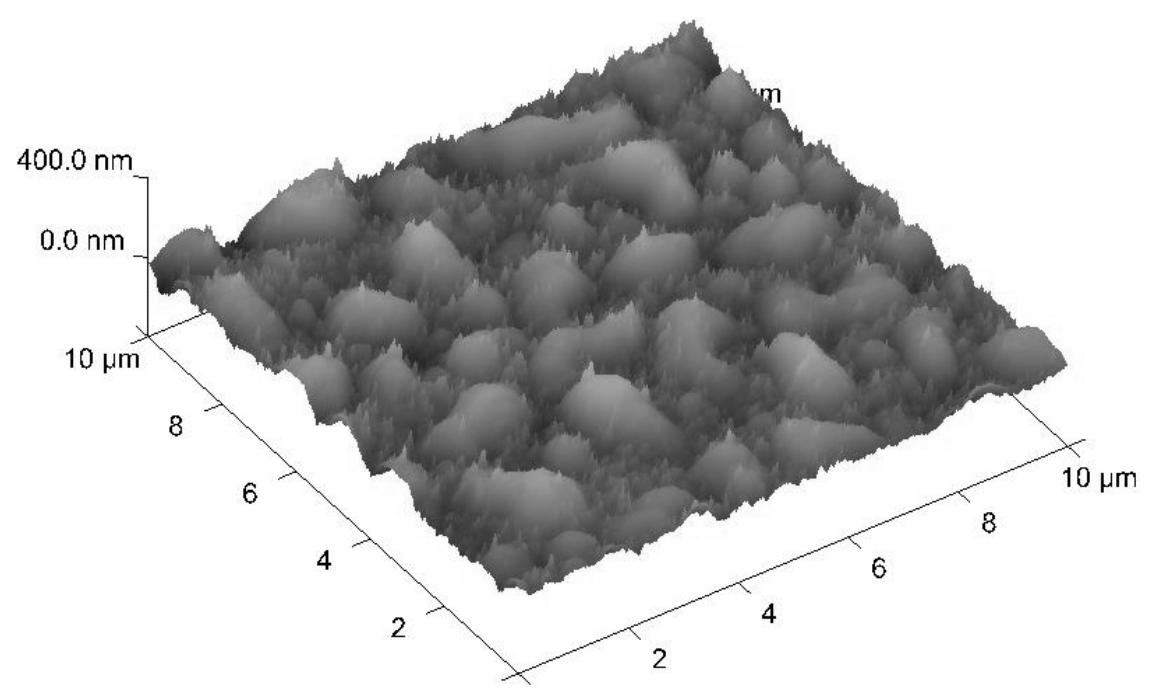

Figure 10: Atomic Force micrograph of copper deposited for 10 minutes



Figure 11: Atomic Force micrograph of aluminium deposited for 10 minutes 




Figure 12: Atomic Force micrograph of copper deposited for 15 minutes



Figure 13: Atomic Force micrograph of aluminium deposited for 15 minutes 


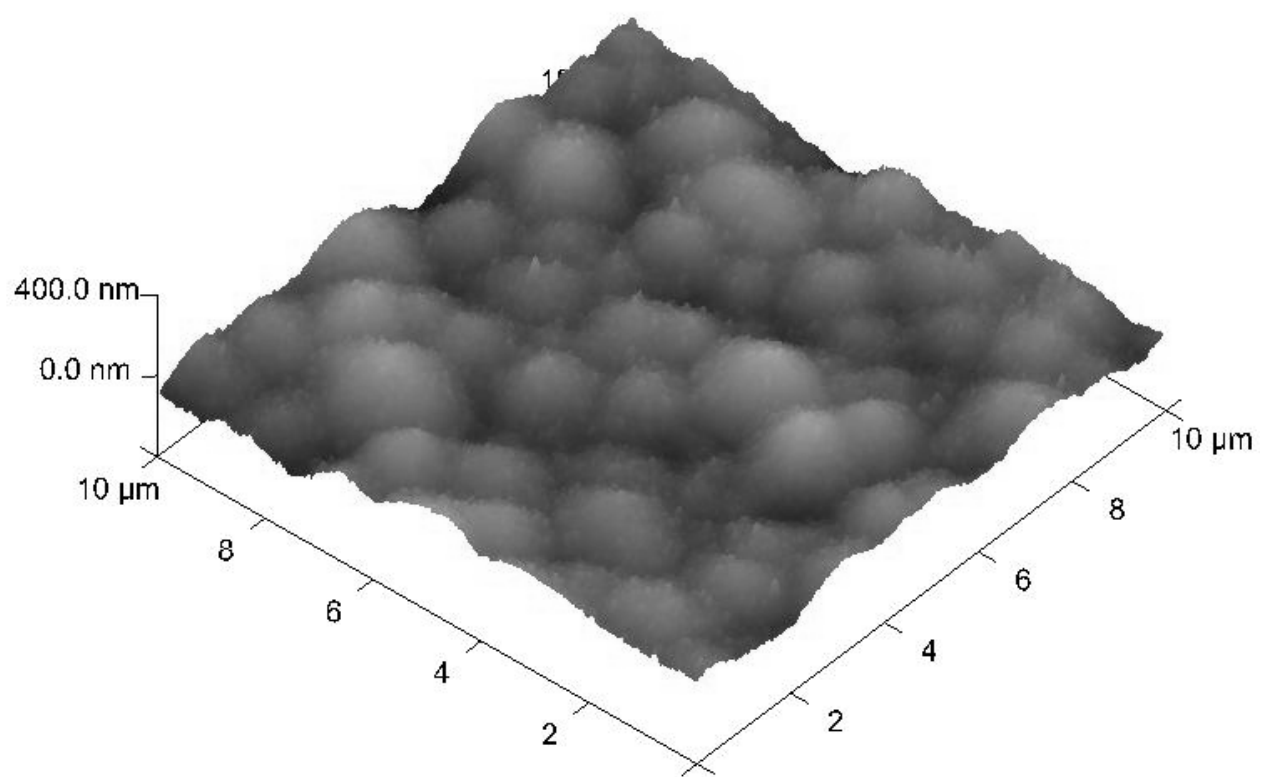

Figure 14: Atomic Force micrograph of copper deposited for 20 minutes

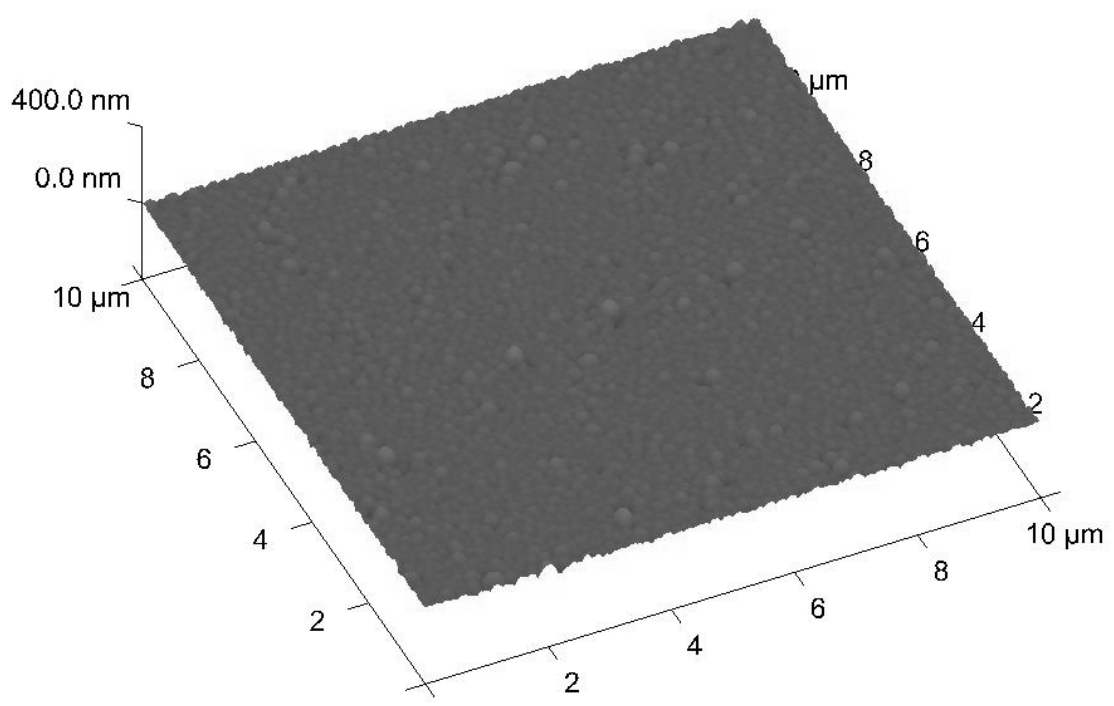

Figure 15: Atomic Force micrograph of aluminium deposited for $\mathbf{2 0}$ minutes

\section{ANALYSIS OF RESULTS}

In Rumpf's study of Van der Waals forces, he observed that they are dependent on the separation distance, dimensions (for example, radius), the Hamaker coefficient, and the rms value of the interacting surfaces (Rabinovich et al. [12]). Rabinovich took the study further and came up with the Rumpf-Rabinovich equation (1), which models the Van der Waals forces experienced when a spherical micro-work part interacts with a flat surface (Rabinovich et al. [12]): 


$$
F=\frac{A R}{6 D^{2}}\left[\frac{1}{1+R / 1.48 r m s}+\frac{1}{[1+1.48 r m s / D]^{2}}\right]
$$

where $\mathrm{F}$ is the Van der Waals force, $\mathrm{A}$ is the Hamaker coefficient (as mentioned earlier, a material property of matter that reflects the intensity of the Van der Waals forces exerted by a given substance shown in Table 2 (Parsegian [10])), $\mathrm{R}$ is the radius of the spherical micro-work part, $D$ is the separation distance between the interacting surface, rms is the root mean square of the surface roughness, as mentioned earlier.

The rms values of the generated topographies conducted in this research are shown in Table 1 and are plotted in Figure 16. Generally it is observed that the rms value increases with an increase in e-beam deposition time.

Rumpf-Rabinovich's equation has two main components in its brackets ( $\mathrm{Li}$ et al. [7], Komvopoulos [6]; Suresh \& Walz [13], Eichenlaub [3]). The first component reveals the effect of surface roughness (in rms) in the noncontact region, and is represented by

1

$1+R / 1.48 r m s$

The second component, which shows the effect of surface roughness for a contact interaction, is given by

$$
1
$$

$\overline{[1+1.48 r m s / D]^{2}}$

In practical situations we have found that, when investigating the limits, the RumpfRabinovoch's second component predominates over the first, since it is a power function.

Further analysis, employing the theory of limits, reveals that as rms value approaches a zero value, Rumpf-Rabinovich's second component approaches a unit value, while as the rms value approaches infinity, Rumpf-Rabinovich's second component approaches a zero value, indicating a reduction in the exerted Van der Waals forces. Therefore, during material handling, the interaction between the pick-up position and the micro work-part should have a higher rms value compared with the placement position.

It was observed that, for an effective picking operation to be realised, the rms value between the gripper and the micro-work part should be less than that between the base material and the micro-work part. In this case, the micro-work part should have a uniform all round surface roughness.

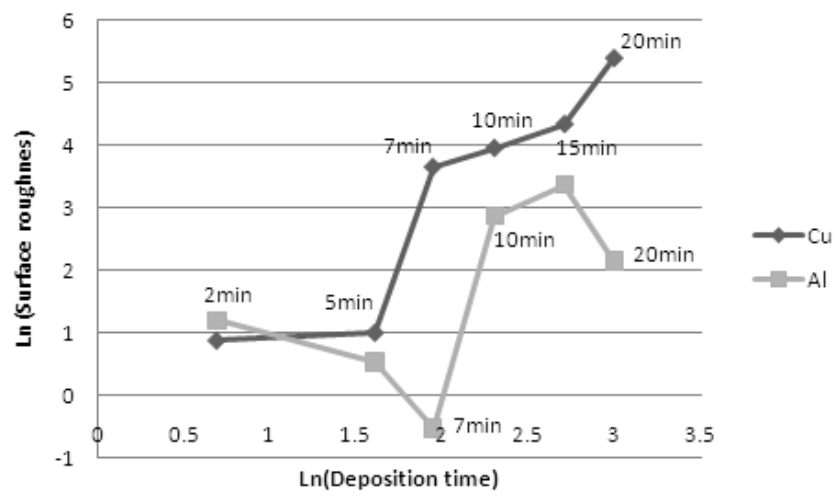

Figure 16: Log-log plot of Copper's rms surface roughness against time 
The effect of the Hamaker coefficient, $A$, has to be investigated before final deductions can be made. Table 2 carries some A values for selected materials. The A values in vacuum are considered to be almost the same as those in air (Bergstrom [1]).

\begin{tabular}{|c|c|c|}
\hline \multicolumn{3}{|c|}{ For compactness the $A$ are given in zeptojoules $(z J)=10^{-21} \mathrm{~J}$} \\
\hline Material & $\begin{array}{c}\text { A across } \\
\text { water }\end{array}$ & $\begin{array}{l}\text { A across } \\
\text { vacuum }\end{array}$ \\
\hline $\begin{array}{l}\text { Organics } \\
\text { Polystyrene } \\
\text { Polycarbonate } \\
\text { Hydrocarbon } \\
\text { (tetradecane, Level 1) } \\
\text { Polymethyl methacrylate } \\
\text { Protein } \\
\text { Teflon }\end{array}$ & $\begin{array}{l}13 \\
3.5 \\
3.8 \\
1.47 \\
5-9,12 \\
0.36\end{array}$ & $\begin{array}{l}79 \\
50.8 \\
47 \\
58.4 \\
\mathrm{n} / \mathrm{a} \\
\text { Almost }=0\end{array}$ \\
\hline $\begin{array}{l}\text { Inorganics } \\
\text { Diamond } \\
\text { Mica (monoclinic) } \\
\text { Mica (Muscovite) } \\
\text { Quartz silicon dioxide } \\
\text { Aluminium oxide } \\
\text { Titanium dioxide rutile } \\
\text { Potassium chloride (cubic } \\
\text { crystal) } \\
\text { Water }\end{array}$ & $\begin{array}{l}138 \\
13.4 \\
2.9 \\
1.6 \\
27.5 \\
60 \\
\\
4.1 \\
\mathrm{n} / \mathrm{a}\end{array}$ & $\begin{array}{l}296 \\
98.6 \\
69.6 \\
66 \\
145 \\
181 \\
\\
55.1 \\
55.1\end{array}$ \\
\hline $\begin{array}{l}\text { Metals } \\
\text { Gold } \\
\text { Silver } \\
\text { Copper }\end{array}$ & $\begin{array}{l}90 \text { to } 300 \\
100 \text { to } 400 \\
300\end{array}$ & $\begin{array}{l}200 \text { to } 400 \\
200 \text { to } 500 \\
400\end{array}$ \\
\hline
\end{tabular}

Table 2: Comparison of Hamaker coefficients (Parsegian [9])

From Table 2, the Hamaker coefficient for copper is 400zJ and for aluminium it is taken as 145z since it easily oxidises once in operation. Figure 17 shows the plot of the Van der Waals forces with respect to the deposition times, taking into consideration the Hamaker coefficients of copper and aluminium. The Rumpf-Rabinovich equation containing the contact component only is used to determine the Van der Waals forces' intensity, as discussed earlier.

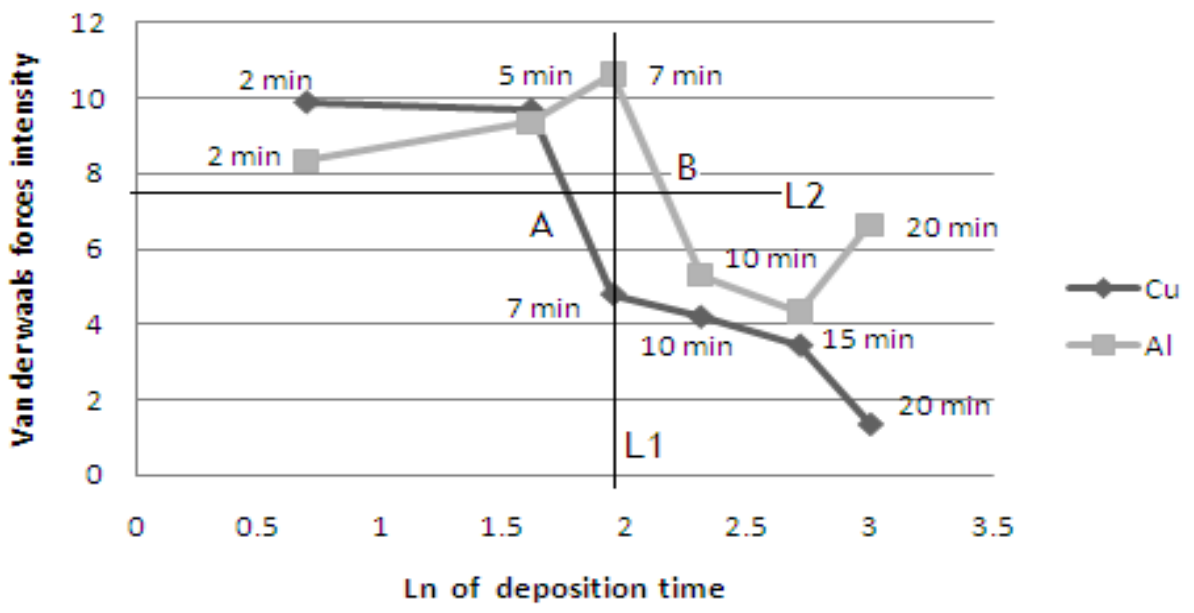

Figure 17: Log-log plot of Van der Waals' intensity and deposition time 
An analysis of Figure 17 reveals that (in the case of copper) the Van der Waals forces' intensity decreases with an increase in deposition time, since the rms value increases. On the other hand, the Van der Waals forces for aluminium (Al) increase during the 2 to 7 minutes deposition times, and then decrease afterwards. In the 10 to 15 minutes deposition range, there is no significant difference between the $\mathrm{Cu}$ and $\mathrm{Al}$ graphs. The 20 minutes deposition time shows a widening gap between the two graphs, but the Van der Waals forces are not as significant as the 7 minutes deposition time.

Therefore, our optimisable region is between 5 minutes and 10 minutes deposition times. Further analysis shows that the optimum lies along line L1, which joins the 7 minutes points on both graphs. Consequently, two extremes are identified in which copper of $38.3 \mathrm{rms}$ surface roughness would be suitable for the pick-up position, and aluminium (of $17.5 \mathrm{rms}$ ) for the placement position in a material handling system.

In this scenario, an appropriate optimum micro-gripper should have Van der Waals force intensity lying in the middle between the two extremes. A value of 7.71 is found to be the average value of the two extremes where the graphs intersect with L1.

In order to find the deposition time for an optimum micro-gripper's topography, line L2 is drawn perpendicular to L1 passing through 7.71. Line L2 intersects the Cu graph at point A and the $\mathrm{Al}$ graph at $\mathrm{B}$. By linear interpolation, the coordinates of $\mathrm{A}$ are $(1.74 ; 7.71)$ and of $\mathrm{B}$ (2.14 and 7.71). Since the $\mathrm{Cu}$ and $\mathrm{Al}$ graphs are natural logarithmic plots, it follows that point $A$ corresponds to a deposition time of $5.75 \mathrm{~min}$ and $B$ to $8.82 \mathrm{~min}$. Therefore the micro-gripper can be either copper, which has been e-beam deposited for 5.75 minutes, or aluminium deposited for 8.82 minutes. Corresponding rms values are 8.2 for copper and 5.3 for aluminium after interpolation using Figure 16.

\section{CONCLUSION}

E-beam depositions at a rate of 0.6-1.2 Angstroms/ second, at vacuum pressure between

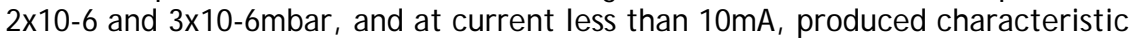
topographies for copper and aluminium. Characteristic rms values were obtained for each deposition time of a given material. The application of Rumpf-Rabinovich's surface roughness formula for determination of the Van der Waals force intensity exerted by the generated topographies revealed an optimisable region for micro-material handling purposes. The graphical plots of the Van der Waals force intensity against deposition time yielded 7 minutes as the optimum time. A corresponding copper topography of $38.3 \mathrm{rms}$ surface roughness proved to be suitable for the pick-up position, and aluminium of $17.5 \mathrm{rms}$ for the placement position. Further analysis proved that, in this scenario, an aluminium micro-gripper with surface topography generated by a 5.75-minute e-beam deposition (which yields an rms value of 8.2) would work optimally. An alternative would be a copper gripper of $5.3 \mathrm{rms}$ surface roughness generated by an 8.82-minute e-beam deposition. For this optimal solution to be realised, a micro-work part of an all-round uniform surface roughness should be used.

\section{REFERENCES}

[1] Bergstrom, L. 1997. Hamaker constants of inorganic materials, Advances in Colloid and Interface Science, Vol. 70, 125-169.

[2] Debrincat, D.P., Solnordal, C.B. and van Deventer, J.S.J. 2008. Characterisation of interparticle forces within agglomerated metallurgical powders, Powder Technology, 182, 388-397.

[3] Eichenlaub, S., Gelb, A. and Beaudoin, S. 2004. Roughness models for particle adhesion, J ournal of Colloid and Interface Science, 280, 289-298.

[4] Feddema, T., J ohn, Xavier P. and Brown, R. 2001. Micro-assembly planning with van der Waals force, J ournal of Micromechatronics, Vol. 1(2), 139-153.

[5] Fukuda T. \& Arai F. 1999. Microrobotics, Handbook of industrial robotics. New York: J ohn Wiley $\&$ Sons, Inc. , 187-198.

[6] Komvopoulos, K. 1996. Surface engineering and microtribology for microelectro-mechanical systems, Wear, 200, 305-327. 
[7] Li, Q., Rudolph V. and Peukert, W. 2006. London-Van der Waals adhesiveness of rough particles, Powder Technology, 161, 248-255.

[8] Matope, S. and van der Merwe, A.F. 2010. Micro-material handling employing Van der Waals forces, Proceedings of the International Conference on Competitive Manufacturing (COMA 10), Stellenbosch University, 3-5 February 2010, 261-267.

[9] Okazaki, Y., Mishima, N. and Ashida, K. 2004. Microfactory - Concept, history, and developments, J ournal of Manufacturing Science and Engineering, Vol. 126, 837-844.

[10] Parsegian, V.A. 2006. Van der Waals forces: A handbook for biologists, chemists, engineers, and physicists. Cambridge University Press.

[11] Raatz, A. and Hesselbasch, J. 2007. High-precision and micro assembly, Proceedings of the International Conference on Competitive Manufacturing, COMA'07, J an-Feb, 321-326.

[12] Rabinovich, Y.I., Adler, J.J., Ata, A., Singh, R.K. and Moudgil, B. M. 2000. Adhesion between nanoscale rough surfaces II. Measurement and comparison with theory, J ournal of Colloid and Interface Science, 232, 17-24.

[13] Suresh, L., Suresh, Y. and Walz, J.Y. 1997. Direct measurement of the effect of surface roughness on the colloidal forces between a particle and flat plate, Journal of Colloid And Interface Science, 196, 177-190.

[14] Thoreson, E.J., Martin, J. and Burnham, N.A. 2006. The role of few-asperity contacts in adhesion, J ournal of Colloid and Interface Science, 298, 94-101.

[15] Van der Merwe, A.F. and Matope, S. 2009. The physical design of micro-grippers actuated by Van der Waals forces for use in micro-material handling. Proceedings of the $23^{\text {rd }}$ SAllE Annual Conference, Roodevallei Country Lodge, Pretoria, 28-30 October 2009, 178-188.

[16] Zhang, H.W., Wang, J.B., Ye, H.F. and Wang, L. 2007. Parametric variational principle and quadratic programming method for Van der Waals force simulation of parallel and cross nanotubes, International J ournal of Solids and Structures, 44, 2783-2801. 